\title{
Possibility of using retrograde reperfusion renal graft to reduce ischemic-reperfusion injury
}

\author{
Myltykbay Rysmakhanov, Gany Kuttymuratov
}

Department of General Surgery and Transplantation, Aktobe Medical Center, Aktobe, Kazakhstan

Background: Today, ischemic-reperfusion injury (IRI) of a renal graft remains an urgent problem. The aim was to study the possibility of the effect of retrograde reperfusion of a renal transplant on the reduction of IRI in kidney transplantation.

Methods: We performed 72 living-donor kidney transplants using retrograde graft reperfusion methods. After standard laparoscopic nephrectomy, the renal graft was flushed with histidine-tryptophan-ketoglutarate solution with heparin. The mean time of cold ischemia was $28 \pm 11$ minutes, and the duration of secondary warm ischemia was $22 \pm 8$ minutes. After the venous anastomosis of the "end-to-side" type was applied between the vein of the donor kidney and the external iliac vein of the recipient, retrograde reperfusion of the kidney with venous blood was performed. Anastomosis was then initiated between the renal artery and the external or common iliac artery of the recipient. The average duration of the arterial anastomosis was $15 \pm 2.6$ minutes. Thereafter, antegrade arterial renal reperfusion was performed.

Results: In all cases, the graft function was satisfactory. Complications in the form of vascular thrombosis were not observed, during the operation there were no reanastomoses. Immunosuppression was carried out according to a three-component scheme; calcineurin inhibitor+mycophenolate mofetil+steroid with induction by basiliximab. The normalization of serum creatinine and urea levels was noted on average on the 4th day after surgery. On postoperative days 9-11 in three patients were diagnosed with urological complications-urinary leakage. Complications were eliminated by surgery. There were no indications for diagnostic biopsy of the renal graft.

Conclusions: The results of the analysis of the initial experience of kidney transplantation using retrograde reperfusion underline the fact that this technique does not impair graft function. The positive effect of retrograde reperfusion in reducing the IRI of the kidney transplant will be the subject of our further research.

Corresponding author: Myltykbay Rysmakhanov

E-mail: mrtransplantolog@gmail.com

(C) The Korean Society for Transplantation

This is an Open Access article distributed under the terms of the Creative Commons Attribution Non-Commercial License (http://creativecommons.org/licenses/by-nc/4.0/) which permits unrestricted non-commercial use, distribution, and reproduction in any medium, provided the original work is properly cited. 